\title{
Turistificação e Patrimonialização na Representação do Espaço: uma Análise sob a Perspectiva da Tríade Lefebvriana ${ }^{1}$
}

\section{Turistification and Patrimonialization in the Representation of Space: an Analysis Using a Lefebvrian Triad Perspective}

\author{
Débora Rodrigues de Oliveira Serrai \\ Universidade Federal do Pará \\ Belém, Brasil
}

\begin{abstract}
Resumo: o presente artigo aborda os processos de turistificação e patrimonialização na produção do espaço a partir da tríade dialética desenvolvida por Lefebvre (2013), visando relacioná-los à dimensão da representação do espaço. A análise contribui para a compreensão de que a concepção do espaço dada por tais processos implica nas dimensões do percebido e do vivido. Como procedimento metodológico foi utilizado o levantamento e a análise bibliográfica referentes à produção do espaço e aos supracitados processos de turistificação e patrimonialização. Com base em dados empíricos apresentados pelos autores abordados, revela-se, como resultado, que nas concepções do espaço para o turismo que se utilizam de bens patrimoniais faz-se necessário considerar os espaços percebido e vivido a fim de se evitar que projetos nessas áreas sejam frustrados e, principalmente, ocasionem efeitos prejudiciais a moradores e visitantes
\end{abstract}

Palavras-chaves: Turistificação; Patrimonialização; Produção do Espaço; Representação do Espaço.

\begin{abstract}
This article treats the processes of touristification and patrimonialization in the production of recreation space using a dialectic triad perspective first developed by Lefebvre (2013). By associating these two processes to the dimension of spatial representation an understanding is gained of space as a process involving perceived and lived dimensions. The present study uses survey methods and bibliographical analysis concerning the production of space as related to turistification and patrimonialization. Empirical data is presented to show how conceptions of tourist space are used as patrimonial assets. The necessary of considering how tourist spaces are perceived and lived in is shown to be fundamental for avoiding the failure of projects undertaken in these areas which can cause detrimental effects to residents and visitors.
\end{abstract}

Keywords: Touristification; Patrimonialization; Production of Space; Representation of Space.

\footnotetext{
'Mestranda do Programa de Pós-Graduação em Geografia. debserra1980@hotmail.com. https://orcid. org/0000-0002-2895-8910
} 


\section{Introdução}

Ao abordar a produção do espaço, Henry Lefebvre se torna um autor importante para as análises geográficas no modo de produção capitalista, contribuindo para uma visão ampla do espaço social com a construção da tríade dialética que envolve as práticas espaciais, os espaços de representação e a representação do espaço, que correspondem aos espaços percebido, vivido e concebido.

Atuando de modo cada vez mais intenso na produção do espaço com o avanço do modo de produção capitalista, os processos de turistificação e patrimonialização se relacionam entre si e se assemelham, conforme Cruz (2017), por terem iniciado na Europa e por terem se globalizado atendendo a interesses mercadológicos.

O objetivo do presente estudo é relacionar os referidos processos de turistificação e patrimonialização à dimensão da representação do espaço ou do espaço concebido, considerado por Lefebvre (2013) como espaço dominante, mas que apresenta interdependência com os espaços percebido e vivido.

A análise do modo como se concebem processos que atuam na produção do espaço é reveladora dos interesses dos seus agentes hegemônicos, bem como dos seus efeitos sobre as percepções e vivências espaciais de indivíduos e grupos sociais de modo que, no que se refere à turistificação e patrimonialização, estudos com essa abordagem podem contribuir para concepções do espaço mais adequadas às necessidades de seus habitantes e visitantes.

Para tanto, utilizou-se como metodologia o levantamento e a análise bibliográfica referentes à produção do espaço e aos supracitados processos de turistificação e patrimonialização.

A estrutura do presente artigo se divide em três seções, que abordam, respectivamente, a tríade desenvolvida por Henry Lefebvre para as análises da produção do espaço, considerações sobre a inter-relação dos processos de turistificação e patrimonialização e, finalmente, a relação de tais processos com a representação do espaço.

\section{A Tríade Lefebvriana na Produção do Espaço}

A abordagem geográfica dos mais diversos fenômenos se dá pela sua relação com o espaço, o qual está presente em diversos ramos do conhecimento científico, mas, na geografia, se tornou central, tido como um ponto de partida para estudos mais voltados à criticidade. A construção de seu conceito, porém, se dá a partir de contribuições externas às elaboradas pelos geógrafos, destacando-se os estudos de Henri Lefebvre.

Lefebvre se refere a um conhecimento do espaço à escala global, sendo ele "essencialmente ligado à reprodução das relações (sociais) de produção" (LEFEBVRE, 2008a, p. 48), sendo, ainda, um produto da história. Para ele:

O espaço (social) não é uma coisa entre as coisas, um produto qualquer entre os produtos: mas, envolve as coisas produzidas e compreende suas relações e sua coexistência e simultaneidade: em sua ordem e/ou desordem (relativos). De modo que, resultado de uma sequência e de um conjunto de operações, não pode reduzir-se à condição de simples objeto. (LEFEBVRE, 2013, p. 129, tradução nossa) 
Para Carlos (2017a), Lefebvre não trata do conceito de espaço, mas sim da "produção do espaço", dado que a noção de produção, presente na teoria marxista que o influenciou, possibilita identificar o momento histórico em que o espaço se torna necessário para a reprodução de um modo de produção, importando, ainda, identificar os sujeitos desse processo: o Estado, o capital e os sujeitos sociais.

Sendo compreendido por meio de uma relação social inerente a relações de propriedade e ligado às forças produtivas, o espaço para Lefebvre (2013) é um produto que se consome, mas é também meio de produção, dado que o que configura o espaço é também determinado por ele. Como meio de produção, ele não pode ser separado das forças produtivas, da divisão social do trabalho, da natureza, do Estado ou das superestruturas.

Lefebvre (2008a) entende que as sociedades sempre produziram o seu espaço na superfície do solo, mas a ampliação das forças produtivas tem permitido se produzir o espaço como um todo. O espaço não é inocente, dado que ele é produzido de acordo com as visões e interesses dos seus produtores.

Desse modo, considerar o espaço como neutro, por não se notar as relações que existem dentro de sua forma, esconde a existência de um sujeito que atua para manter suas condições. Esse sujeito, para Lefebvre (2013), é o Estado, com sua base em classes sociais e frações de classe.

Lefebvre (1972, p. 147) afirma que:

O Estado tem, com efeito, interesses próprios e por isso tende, em particular no Ocidente e em França, a colocar-se acima da sociedade, a instaurar-se, mascarando as contradições dessa sociedade, esmagando-as pela força repressiva ou dissimulando-as num nevoeiro ideológico, em resumo, tende a fazer imperar uma "razão de Estado" confundida - ideologicamente - com a razão em geral. Além da burocracia, e pelas mesmas razões, o Estado mantém um aparelho repressivo: exército, polícia, aparelho judiciário, etc.

Assim, a partir de hipóteses, o autor propõe a análise crítica do espaço, tal como Marx realizou na economia. Numa analogia à substituição da análise das coisas em si mesmas pela análise crítica da atividade produtiva, tarefa executada por Marx, o autor compreende a necessidade de ir além da análise das coisas no espaço para se descobrir as relações sociais nelas presentes. Afirma que a tendência tem sido fragmentar o espaço pela divisão social do trabalho, considerando-se o espaço como receptáculo passivo. Nessa analogia, seria possível também investigar a fetichismo do espaço (LEFEBVRE, 2013).

Considerando a análise de Lefebvre (2013), que nos revela a transformação do espaço em mercadoria, observa-se que esse processo evolui para que as cidades passem a competir entre si por sua inserção num mercado mundial, que se movimenta de modo articulado com outros mercados, dentre eles o do turismo, fazendo-se necessário o uso de novas estratégias espaciais, conforme aponta Sanchez (2001).

Para a referida autora, o mercado do turismo "tem fortes imbricações com o mercado de cidades e, apoiado nesta relação, constrói suas segmentações e grupos-alvo no mercado, como o turismo urbano, [...], o turismo cultural, o turismo de compras, de jovens ou de terceira idade" (SANCHEZ, 2001, p. 34). 
Pode-se afirmar que o turismo se torna, portanto, uma atividade que possibilita a compreensão da importância da análise do espaço no avanço dos estudos marxistas, conforme se propõe Lefebvre (1973), uma vez que para ele a ocupação e a produção do espaço se tornaram cada vez mais necessários para a continuidade do modo de produção capitalista.

Ademais, a análise da atividade turística permite, ainda, que se visualizem os já mencionados aspectos relativos ao espaço, que superam a ideia de sua passividade, destacando-se o fato de que ele é ao mesmo tempo um produto, cujo consumo se dá claramente no turismo, mas também um meio de produção, ou seja, objeto de trabalho ou matéria prima para se tornar mercadoria, o chamado produto turístico.

Buscando aprofundar a análise da produção do espaço como mercadoria, é importante incluir uma das principais contribuições de Lefebvre para esclarecer a relação entre o espaço e a reprodução das relações sociais de produção: a dialética tridimensional do espaço.

A princípio, ressalta-se que, para Schmid (2012), a teoria lefebvriana da produção do espaço tem sido interpretada, por parte dos pesquisadores, de modo equivocado, desconsiderando-se o que para ele são aspectos fundamentais: "(1) sua versão triádica da dialética, desenvolvida com base em Hegel, Marx e Nietzsche; (2) sua teoria da linguagem baseada em Nietzsche; e (3) a influência da fenomenologia francesa em seu pensamento" (p. 89), havendo, portanto, a necessidade da reconstrução dessa teoria.

Assim, no que se refere à versão triádica da dialética, Lefebvre (2013) apresenta as dimensões das práticas espaciais, das representações do espaço e dos espaços de representação, às quais correspondem, respectivamente, três tipos de espaço: percebido, concebido e vivido.

a) A prática espacial de uma sociedade produz seu espaço (...): Em que consiste a prática espacial no neo-capitalismo? Expressa uma estreita associação no espaço percebido, entre a realidade cotidiana (o uso do tempo) e a realidade urbana (os percursos e redes que se ligam aos lugares do trabalho, da vida "privada", de ócio).

b) As representações do espaço, ou seja, o espaço concebido, o espaço dos cientistas, planejadores, urbanistas, tecnocratas fragmentadores, engenheiros sociais e até o de certo tipo de artistas próximos à cientificidade, todos os quais identificam o vivido e o percebido com o concebido (...).

c) Os espaços de representação, ou seja, o espaço vivido através das imagens e símbolos que o acompanham (...). Trata-se do espaço dominado, isto é, passivamente experimentado, que a imaginação deseja modificar e tomar. (LEFEBVRE, 2013, p. 97-98, tradução nossa)

Ressalta-se que Lefebvre (2013) compreende que as três dimensões do espaço interferem na sua produção de diferentes maneiras, considerando as suas características, seu modo de produção e o momento histórico, sendo que a relação entre elas apresenta uma tensão permanente.

Desse modo, Schmid (2012) esclarece a necessidade de que se dê exatamente o mesmo valor às três referidas dimensões, de modo que as análises devem considerar que 
o espaço é ao mesmo tempo concebido, percebido e vivido. Para ele, essas dimensões "constituem uma unidade dialética contraditória. É uma tripla determinação: o espaço emerge somente da interação de todas as três" (p. 105).

Ainda em Schmid (2012), é possível identificar a influência da perspectiva fenomenológica, mas ao mesmo tempo materialista, na tridimensionalidade proposta por Lefebvre, a qual pode se relacionar ao indivíduo ou à sociedade. De modo claro, ele diferencia e relaciona os três espaços:

- $\quad$ Espaço percebido: o espaço tem um aspecto perceptível que pode ser apreendido por meio dos sentidos. (...) Esse aspecto sensualmente perceptivo do espaço relaciona-se diretamente com a materialidade dos "elementos" que constituem o "espaço".

- Espaço concebido: o espaço não pode ser percebido enquanto tal sem ter sido concebido previamente em pensamento.

- Espaço vivido: (...) Essa dimensão significa o mundo assim como ele é experimentado pelos seres humanos na prática de sua vida cotidiana. Neste ponto, Lefebvre é inequívoco: o vivido, a experiência prática, não se deixa exaurir pela análise teórica. Sempre permanece (...) o que não é passível de análise apesar de ser o mais valioso resíduo, que só pode ser expresso por meio de meios artísticos. (Schmid, 2012, p. 103)

No presente estudo, ressalta-se a importância dada por Lefebvre à dimensão espacial para uma continuidade do que se propunha Karl Marx, tanto por colocá-lo para além da localização de onde se consome e produz, dado que, como observa Gottdiener (2010), ele se torna uma força produtiva, a partir da sua forma ou design, como pelo seu avanço no desenvolvimento de uma dialética não mais binária, mas triádica, conforme explanado por autores como Schmid (2012).

A tríade espacial desenvolvida por Lefebvre (2013) pode ser utilizada para a análise de diversos fenômenos que ocorrem na produção e na reprodução do espaço, dentre eles a turistificação e a patrimonialização, processos que, considerando as transformações do capitalismo, atendem à lógica do mercado, conforme Cruz (2007).

Partindo da concepção de Lefebvre (2013) de que o espaço é socialmente produzido, de que nele se dão as contradições relativas ao modo de produção vigente e que ele se apresenta por uma tríade dialética formada pelo percebido, concebido e vivido, também chamadas de práticas espaciais, representação do espaço e espaço de representação, observa-se que os processos de turistificação e patrimonialização exercem influência sobre a dimensão da representação do espaço, no ato de se buscar definir o que pode ou não ser considerado atrativo turístico e patrimônio, consequentemente, influenciam também as práticas espaciais e o espaço de representação.

Assim, a partir da tríade dialética lefebvriana para a análise do espaço, considera-se que a turistificação e patrimonialização atuam na representação do espaço, quando especialistas definem os bens de maior atratividade, importância e maior relação com a devoção a partir de um saber técnico, mas que também pode ser ideológico para atender aos interesses de determinados grupos. 


\section{A Inter-relação entre os Processos de Turistificação e Patrimonialização}

Para uma análise mais densa sobre como a turistificação e a patrimonialização podem ser interpretadas a partir da dimensão da representação do espaço, faz-se necessário o levantamento de diversos estudos, sobretudo sob o enfoque geográfico, que esclareçam os referidos processos e como eles se relacionam entre si.

Diversos autores enfocam a relação entre a atividade turística e os bens patrimonializados, a exemplo de Bertoncello (2011), que ressalta que essa relação "pode ser considerada como um núcleo fundamental para compreender tanto as formas como o turismo tem sido organizado na atualidade, como o rol e a importância que o patrimônio também tem adquirido, ambos se requerem e se alimentam mutuamente" (BERTONCELLO, 2011, p. 51, tradução nossa).

O presente estudo destaca as abordagens que analisam a turistificação e patrimonialização como integrantes do processo de produção e reprodução do espaço, iniciando-se por Carlos (2017b), para quem o turismo faz parte do processo de acumulação capitalista, tornando-se uma atividade estratégica para as economias locais no momento em que a indústria passa por transformações que reduzem sua capacidade geradora de empregos.

Relacionando patrimônio e turismo, a referida autora observa que o patrimônio "surge da possibilidade de congelar, num determinado lugar, a representação das relações sociais (...) que permitiram a construção de uma história coletiva (...)" (Carlos 2017b, p. 27), mas que é tido como uma particularidade do espaço passível de ser consumida ou vendida, de modo que a história dos lugares perde seu conteúdo ganhando valor de troca no mercado.

Para Cruz (2017), patrimonialização e turistificação são processos inter-relacionados. Ela afirma que o turismo massificado "é expressão do processo de mundialização que consagra a articulação entre essa atividade e o patrimônio cultural, convertido em objeto de consumo e alocado numa aparente encruzilhada entre valor de uso e valor de troca" (CRUZ, 2017, p. 10).

A referida autora compreende que o debate patrimonial, institucionalizado no século XVIII, e o desenvolvimento do turismo como atividade econômica organizada, iniciado no século XIX, são processos socioculturais "distintos nas suas gênesis, mas convergentes no que tange aos interesses de agentes sociais envolvidos com sua organização" (CRUZ, 2017, p. 9-10).

Desse modo, há agentes presentes simultaneamente nesses dois processos, mas a sua identificação requer, inicialmente, a compreensão de seus conceitos, pois, apesar de relacionados, eles apresentam especificidades.

Paes (2009) afirma que a patrimonialização envolve:

(...) um conjunto de práticas sociais, desde as mais diversas formas de produção cultural, de saberes simbólicos e técnicos, até os inúmeros processos de institucionalização do patrimônio como tal, que permitem a preservação dos bens culturais. (PAES, 2009, p. 164)

Para a referida autora, a necessidade da preservação está relacionada às dimensões cultural, no sentido de que o ser humano seleciona, por meio da cultura, o que deve ser 
preservado e valorizado; técnica, considerando que o processo de preservação requer saberes, instrumentos e normas específicos, e, por fim, política, pois tanto a seleção, quanto a normatização do que deve ser patrimonializado envolve conflitos de interesses que geram decisões e ações.

Assim, a seleção do que deve ou não ser patrimonializado envolve disputas econômicas, políticas e simbólicas entre seus agentes, de modo que, para Canclini (1999), o patrimônio cultural se torna um recurso para a reprodução tanto das diferenças entre os grupos sociais, quanto da hegemonia de quem tem mais acesso à produção e distribuição dos bens.

Entretanto, o referido autor compreende que não só a desigualdade estrutural entre as classes na formação e apropriação do patrimônio deve ser considerada nas análises, pois "a sociedade não se desenvolve somente mediante a reprodução incessante do capital hegemônico, nem o lugar das classes populares se explica unicamente por sua posição subordinada" (CANCLINI, 1999, p. 19). Ou seja, é necessário considerar também a interação entre os agentes desses processos: o setor privado, o Estado e os movimentos sociais, pois as contradições no uso do patrimônio estão vinculadas a como ocorre essa interação a cada período.

O termo turistificação, por sua vez, tem sido usado nacional e internacionalmente para se referir à apropriação e transformação de espaços para o turismo e ao direcionamento de atividades para o atendimento de visitantes, buscando-se, assim, atender, sobretudo, a interesses mercadológicos. Figueiredo (2008) observa que a turistificação está direcionada à adequação ou criação de espaços para o turismo, sendo que ela:

(...) notadamente um conceito novo, serve para demonstrar um relativo direcionamento de espaços, cidades, ou mesmo cadeias de produção à atividade turística. Esse direcionamento se dá a partir da mudança da conformação da paisagem e do ordenamento espacial, para que se adequem às novas atividades econômicas (FIGUEIREDO, 2008, p. 86).

Numa perspectiva lefebvriana, Carlos (2017b) indica a importância do turismo no desenvolvimento da sociedade urbana, pois ele aponta para a passagem do consumo no espaço (consumo ligado à realização da vida) para o consumo do espaço (espaço como mercadoria) "(...) de modo que a história dos lugares, destituídos de seus conteúdos, ganha valor de troca no mercado" (CARLOS, 2017b, p. 29).

Tratando do processo de turistificação do espaço, a partir de uma abordagem territorial, Fratucci (2008) afirma que ele "(...) compreende tanto o processo de apropriação simbólica de trechos do espaço pelo turista (...), como o processo de dominação pelos agentes econômicos e pelos agentes de governo" (FRATUCCI, 2008, p. 53). Tal concepção revela o território como uma categoria geográfica importante na análise desse processo, considerando-se a atuação dos seus agentes e suas estratégias de apropriação ou dominação de porções espaciais.

Quanto aos agentes de turistificação do espaço, Fratucci (2008) se baseia em Knafou (1996), o qual elenca os turistas, o mercado e os planejadores e promotores "territoriais", 
aqui considerados como o Estado. Fratucci (2008), porém, amplia essa concepção incluindo entre os agentes as comunidades das áreas receptoras.

Assim, mercado e Estado estão presentes como agentes tanto nos processos de patrimonialização, quanto de turistificação, ambos, em geral, apresentando interesses convergentes. Porém, deve-se ressaltar que, na análise sobre as comunidades das áreas receptoras dos lugares onde se desenvolve a atividade turística, incluem-se os movimentos sociais que buscam a preservação de bens culturais, os quais têm interesses, por vezes, divergentes dos demais agentes.

Na origem da relação entre turismo e patrimônio, Bertoncello (2010) situa o turismo no tempo, afirmando que sua expansão se deu após a Segunda Guerra Mundial, com a modalidade denominada turismo de massa, que tem como paradigma o turismo de sol e praia, embora outras modalidades, chamadas de "turismo alternativo" para turistas-consumidores específicos, estejam se difundindo nas últimas décadas. Nessa tendência surge o turismo cultural, mais valorizado socialmente que o turismo de massa e bastante vinculado ao patrimônio, devendo, no entanto, ser analisado de forma mais cuidadosa.

Nesse sentido, Bertoncello (2010) critica o fato de que, apesar de colocado à disposição de todos, apenas quem tem condições de pagar e de fazer turismo tem acesso a esse patrimônio, o que assemelha o turismo cultural de base patrimonial às modalidades turísticas do passado, que o tornaram uma forma de distinção social.

Assim, o referido autor se refere à segmentação do turismo, a qual está vinculada ao mercado, o que se observa em Brasil (2010a), ao afirmar que:

Para o Ministério do Turismo, a segmentação é entendida como uma forma de organizar o turismo para fins de planejamento, gestão e mercado. Os segmentos turísticos podem ser estabelecidos a partir dos elementos de identidade da oferta e também das características e variáveis da demanda. (BRASIL, 2010a, p. 61)

O referido estudo apresenta a segmentação da atividade turística baseada na demanda, na qual se considera variáveis diversas, tais como a sua situação geográfica, socioeconômica, psicográfica e comportamental; e na oferta, a qual se baseia em características que visam atender às diversas demandas, destacando-se, como segmentos prioritários a serem desenvolvidos no Brasil, os turismos cultural, de estudos e intercâmbio, rural, náutico, de esportes, de aventura, de negócios e eventos, de pesca, de sol e praia, e de saúde, além do ecoturismo.

Para o presente estudo, destaca-se o segmento do turismo cultural, o qual "compreende as atividades turísticas relacionadas à vivência do conjunto de elementos significativos do patrimônio histórico e cultural e dos eventos culturais, valorizando e promovendo os bens materiais e imateriais da cultura" (BRASIL, 2010b, p. 15).

Sobre o movimento crescente de produções geográficas acadêmicas voltadas ao patrimônio e sua relação com o turismo, apesar de não se ter localizado pesquisa científica a respeito, supõe-se a predominância de abordagens voltadas ao patrimônio material em relação às pesquisas sobre o imaterial, o que se explicaria pela entrada mais recente dos bens imateriais no rol das políticas preservacionistas. Essa suposição se estende às demais áreas do conhecimento. 
Nigro (2010) afirma que na Geografia do Turismo e na Geografia Urbana, as revitalizações de áreas centrais se destacam na análise do patrimônio. Em relação ao turismo, as análises geográficas são críticas em relação ao consumo do patrimônio, onde se privilegia seu valor estético, dificultando a compreensão dos processos que originaram as construções patrimonializadas e da sua importância nas vivências sociais presentes. No urbano, as análises se dão sobre os processos de revitalização e de reestruturação urbanas, gerando outros processos, como a gentrificação ${ }^{2}$, ambos associados ao incremento da atividade turística, trazendo efeitos sociais questionáveis.

Choay (2001), ao abordar o patrimônio histórico na era da indústria cultural, mostra a relação entre o patrimônio e a indústria cultural na pós-modernidade, na qual os monumentos e o patrimônio apresentam tanto a função de saber e prazer à disposição de todos, quanto a de produto a ser consumido. Essa relação se desdobra em efeitos perversos, como a exclusão de populações economicamente desfavorecidas das áreas patrimonializadas, bem como a banalização ou homogeneização de cidades, sendo necessárias estratégias de conservação a partir de medidas de controle, medidas pedagógicas e políticas urbanas.

Os efeitos perversos apontados por Choay (2001) têm sido discutidos por diversos estudiosos, dos quais se podem destacar os pesquisadores da chamada Geografia do Turismo, a exemplo de Cruz (2012), que, ao relacionar turismo, patrimônio e produção do espaço, aponta diversas contradições no que ela trata como "patrimonialização do patrimônio", referindo-se à "institucionalização de mecanismos de proteção do patrimônio cultural, material e imaterial" (2012, p. 95).

A referida autora, ao discutir o patrimônio cultural situado entre o valor de uso e o valor de troca, observa o predomínio do valor econômico sobre o cultural em relação aos bens a serem preservados. No caso dos bens tangíveis, ela verifica que, buscando a valorização do espaço geográfico e atendendo aos interesses do mercado imobiliário, populações são expulsas das áreas patrimonializadas, independente da relação histórica que elas possuem com essas áreas, de modo que, para se cuidar do patrimônio, se descuida de quem tem vínculo com ele. Ademais, ela afirma que "entre as motivações que levam à patrimonialização de um dado objeto destaca-se o seu valor de uso, mas o que viabiliza a sua existência como tal é o seu valor de troca" (CRUZ, 2012, p. 98), referindo-se à relação de dependência mútua entre o turismo e o bem patrimonializado, visto que cobra-se para o acesso ao bem, mas depende-se dessa cobrança para que o bem seja preservado. A contradição da contradição se dá quando o bem protegido a partir dessa lógica é destruído pelos próprios turistas.

Estando associada à produção global do espaço, a transformação de bens tombados em mercadoria se torna uma estratégia para o mercado de cidades, discutido por Sanchez (2001) ou, ainda no mesmo sentido, pode ser analisada, segundo Cruz (2012), pelo paradigma do empreendedorismo urbano, discutido por Harvey (2005), no qual, com o avanço do neoliberalismo, houve uma mudança na governança urbana de modo que as cidades passaram a se transformar em mercadorias.

Harvey (2005) aponta quatro estratégias básicas para o empreendedorismo urbano, uma delas referente ao turismo ou para além dele, quando a região urbana pode "buscar meIhorar sua posição competitiva com respeito à divisão espacial do consumo" (2005, p. 175), 
o que se dá com investimentos ligados à qualidade de vida para atrair consumidores, incluindo-se a valorização de áreas degradadas. Porém, ao analisar as perspectivas críticas em relação a esse processo, o autor apresenta alguns de seus impactos negativos, ressaltado que tais perspectivas podem revelar potencialidades.

Dentre os problemas advindos do empreendedorismo urbano numa condição de concorrência interurbana, o referido autor observa, entre outras questões, que:

Deve-se reconhecer que, sob a camuflagem de muitos projetos de sucesso, existem alguns problemas sociais e econômicos muito sérios, e que isso, em muitas cidades, está assumindo um caráter geográfico, na forma de uma cidade dupla, com a regeneração de um centro decadente e um mar circundante de pobreza crescente. (HARVEY, 2005, p. 188)

Assim, Cruz (2012) observa que o empreendedorismo urbano, a partir de investimentos do Estado e do mercado, se dá a partir de uma valorização fragmentada do espaço, ou seja, no caso das cidades históricas, eles são voltados para os centros históricos negligenciando a periferia, devido à seletividade espacial do capital e à arena política onde ocorre a produção do espaço. Para ela:

(...) cidades como Ouro Preto, e Tiradentes, por exemplo, objetos de análise de artigos e teses repletos de "rococó" e vazios de fundamento, permanecem e certamente permanecerão fragmentadas, com seus "centros históricos" iluminados e suas periferias opacas - sendo esta a lógica perversa do empreendedorismo urbano e das parcerias público-privadas que o sustenta - até o dia em que o planejamento urbano-territorial venha a ser o meio pelo qual um Estado igualitário atue para produzir um território socialmente mais justo. (CRUZ, 2012, p. 102)

A análise de Costa (2015), desenvolvida em sua tese de doutorado defendida em 2011, se dá nesse sentido. Como hipótese central, referindo-se à patrimonialização pela Unesco, ele sustenta que "(...) dialeticamente, a cidade histórica se universaliza e se decompõe (...)" (COSTA, 2015, p. 26) a partir da própria patrimonialização, processo que a projeta globalmente, mas que, por favorecer apenas a área tombada, apresenta mecanismos que conduzem à fragmentação do território e uma compreensão distorcida do que é Patrimônio Mundial.

Assim, para ele:

Enquanto as políticas urbanas não operarem junto às políticas patrimoniais nos bairros mais apartados do centro, efetivamente, imperará a perversidade da fragmentação articulada do território urbano nas cidades históricas em tela. (...). Devemos, então, (...) entendermos que a cidade como um todo é um documento. (...). Como já dissemos, não podemos acreditar que a preservação vá solucionar, sozinha, problemas urbanos históricos, mas que a solução das problemáticas socioterritoriais da cidade histórica, para além dos limites do tombamento, pode levar a uma democrática patrimonialização. (COSTA 2015, p. 446) 
Utilizando o método dialético, Costa (2015) aponta diversas contradições no processo de patrimonialização global. Ao discutir a autenticidade e integridade do patrimônio como critérios para a inscrição na lista da Unesco, num momento em que se observa o simulacro das cidades, ele traz o exemplo da Carta de Veneza, que permite a refuncionalização de monumentos, ferindo-se, portanto, o critério da autenticidade. Desse modo, a noção de autenticidade tornou-se flexível, dado que as cidades acompanham o movimento histórico. Para o autor, tal flexibilização atende aos objetivos de: "possibilitar a inclusão de bens que sofreram impactos de catástrofes naturais ou humanas, assim, tornando a Lista do Patrimônio Mundial mais representativa" (COSTA, 2015, p. 231), bem como de fomentar a dinâmica econômica dos lugares chancelados, pois, “(...) integram a rede global da nova economia urbana".

Quanto à seletividade do que é patrimonializado, que se dá pela chamada ativação patrimonial, Bertoncello (2010) compreende que ela se baseia nos interesses do presente e não na representatividade do bem no passado e que ela utiliza critérios supostamente objetivos, mascarando a intenção de atender ao mercado, especialmente quando esse bem é usado como atrativo turístico.

Nessa relação entre turismo e patrimônio, o referido autor afirma que a seletividade se dá mais por critérios e interesses das sociedades de origem dos turistas do que das sociedades a quem esse patrimônio pertence e para quem se justifica a patrimonialização. Ademais, ao se buscar atender às expectativas do turismo existe o risco de conflitos com os interesses dos órgãos legitimadores.

Para ele, tais questões colidem com o caráter de bem comum do patrimônio, ou seja, a sua valorização turística pode levar a processos diferenciais de apropriação e a sua privatização pode desvirtuar a essência do patrimônio. Assim, se subverte a sequência da preservação, institucionalização e transformação em atrativo turístico e ela passa a se iniciar pela identificação, via técnicas de marketing, dos interesses dos turistas potenciais, que levam a seleção de bens que atendam a esses interesses e que por essa razão se tornam os bens a serem protegidos e oficialmente patrimonializados.

Assim, infere-se que o que não é interessante turisticamente ou, sendo mais abrangente, economicamente, tende a não ser valorizado como patrimônio, reduzindo-se a possibilidade da diversidade e, nesse sentido, Cruz (2012) aponta uma outra contradição ao afirmar que "o movimento que busca auferir, com a 'patrimonialização do patrimônio', a renda de monopólio, é o mesmo que impede o alcance deste objetivo, posto que, ao estetizar as formas, banaliza-as pelo repetitivo e pelo homogêneo" (CRUZ, 2012, p. 103).

As contradições ora apresentadas são características da produção do espaço no capitalismo e, conforme propósito desse estudo, enfatiza-se, a seguir, a relação da representação do espaço com a turistificação e a patrimonialização.

\section{A Turistificação e a Patrimonialização na Representação do Espaço}

Em relação ao processo de turistificação, o qual se insere na produção e reprodução do espaço a partir dos interesses de diversos agentes, Cruz (2007) compreende que, dentre eles, o Estado e o mercado são os que atuam de modo hegemônico. 
Tal compreensão pode ser estendida ao processo de patrimonialização, considerando todo o exposto no presente estudo, ressaltando-se que a atuação do Estado e do mercado, em ambos os processos, se dá pela seleção, por meio dos planejadores e da sua concepção do espaço, do que deve ou não atrair turistas e/ou ser preservado. E, nesse sentido, é possível a análise de tais processos na dimensão do espaço concebido, que, para Lefebvre (2013, p. 97), "é o espaço dominante em qualquer sociedade (ou modo de produção)" (tradução nossa).

Referindo-se ao espaço do ócio e seu consumo, Lefebvre (2013, p. 116, tradução nossa) afirma que "(...) na prática espacial do neocapitalismo, com os transportes aéreos, as representações do espaço permitem manipular os espaços de representação (sol e mar, festa, gasto e desperdício)". A partir dessa afirmação, infere-se que as práticas espaciais contemporâneas capitalistas, relativas a bens culturais materiais e imateriais, com os processos de turistificação e patrimonialização atuando na concepção do espaço a partir de interesses mercadológicos, alteram o sentido e, portanto, os espaços de representação relativos a esses bens.

Todavia, essas alterações nos espaços de representação podem gerar conflitos espaciais, principalmente quando se dão pela imposição de interesses de alguns grupos sociais, a exemplo do que ocorre na elaboração e implementação de diversas políticas públicas no Brasil, inclusive nas que se referem ao turismo e ao patrimônio.

Nesse sentido, em relação à turistificação, a análise de Malta (2018) sobre as políticas públicas de turismo no Brasil, referindo-se ao período de 1930 até o plano nacional do triênio 2013-2016, revela que elas "foram e são pouco participativas, centradas nas tomadas de decisão dos poderes públicos e foram relegadas, em todos os governos estudados, a um papel secundário" (MALTA, 2018, p. 83).

Em relação a conflitos observados no processo de patrimonialização, estudiosos do tema nos apresentam exemplos como os projetos de tombamento "Paisagens Cariocas" e "Cais do Valongo", ambos no Rio de Janeiro, nos quais Ribeiro (2017) observa que o primeiro se deu de modo impositivo e o segundo por pressão popular. Para o autor, o reconhecimento do Estado não basta, sendo necessário ampliá-lo para diferentes setores da sociedade e, dessa forma, nos dois projetos citados, a legitimidade da patrimonialização depende de que a população os acate e os aceite. Referindo-se ao "Paisagens Cariocas", ele afirma que "o fato da inscrição ter sido feita de 'cima pra baixo', não anula a possibilidade de esta inscrição se tornar um instrumento de uso verdadeiramente democrático e constituidor de cidadanias, entretanto, isto ainda permanece como devir" (RIBEIRO, 2017, p. 63). Porém, compreende-se que, devido aos mecanismos de participação popular na gestão do patrimônio ainda apresentarem entraves, a apropriação da população pela patrimonialização desde o início do processo, no que se refere também à seleção dos bens, seria fundamental para que o ideal apresentado pelo autor se efetivasse.

Ademais, as discussões sobre a participação popular nas políticas públicas merecem análises aprofundadas, pois, como aponta Demo (1996), deve-se considerar, inicialmente, o processo histórico de dominação e opressão, onde a participação só é interessante para a classe hegemônica quando ela é consentida e tutelada, legitimando a ordem vigente. A verdadeira participação, porém, conforme o autor, faz parte de um processo de conquista a partir da superação da dominação preexistente. 
No que se refere à institucionalização dos processos de patrimonialização e turistificação, observa-se que ela interfere na produção do espaço de acordo com a concepção de seus agentes, das disputas entre eles em cada campo (BOURDIEU, 2003), nas quais os interesses da classe hegemônica, em cada processo, tendem a prevalecer. Todavia, é necessário atentar para a constante relação dialética entre as dimensões da tríade espacial apontada por Lefebvre (2013) para evitar a impressão de que, como espaço dominante, o espaço concebido se efetiva desconsiderando o vivido e o percebido.

Nesse sentido, entre os estudos geográficos referentes a turismo e patrimônio, a análise de Trindade Jr (2013) sobre o processo de renovação e reapropriação do espaço na área central de Belém oferece elementos reveladores, dado que ele discute a relação entre patrimônio, vivência e representação do espaço urbano. Segundo esse autor, as intervenções realizadas sobre o patrimônio da referida cidade não articulam a sua conservação com as vivências preexistentes, imperando a lógica moderna e dita eficiente nos projetos voltados para o marketing urbano. Por conseguinte, tal lógica, que faz parte da representação do espaço, ou seja, da concepção do espaço por agentes hegemônicos ligados, entre outros, à patrimonialização e à turistificação, ignora, segundo o autor, os conteúdos sociais presentes no seu núcleo central e na zona periférica do centro, implementando serviços sofisticados em áreas habitadas pela classe média baixa, de comércio popular e com forte presença de ambulantes. Porém, ao ignorar esses conteúdos, os quais estão vinculados ao vivido e ao percebido pela população local, há o risco das intervenções não atenderem às expectativas pelas quais elas foram concebidas, o que o autor exemplifica com os projetos de requalificação urbana da década de 1980 na Feira do Açaí e na Ladeira do Castelo. Em ambos os casos, observou-se a falta de continuidade no seu uso pela população de maior renda, bem como por turistas.

Em relação aos citados projetos, bem como aos implementados a partir da década de 1990, como a Estação das Docas e a Estação Gasômetro, o referido autor revela que, na dimensão da representação do espaço, a renomeação de espaços requalificados é estratégica para a afirmação dos novos conteúdos que se pretende dar ao patrimônio. Ou seja, os nomes dos projetos se tornam usuais para a população e contribuem para a mudança de sentido que se pretende dar a esses espaços. Assim, o nome "estação", sugere um sentido de pausa, que fica esvaziado ao servir apenas para quem tem condições de consumir em tais espaços. Para os que não têm tal condição, o termo fica com sentido de espaço de passagem, o que revela um esvaziamento tanto do espaço público, que se torna coletivo, quanto do espaço do cidadão, que se torna espaço do consumidor (TRINDADE JR, 2013).

Outra característica das intervenções desse período, ainda segundo o referido autor, é a criação de uma nova relação com o rio, de modo a se negativar a imagem propiciada pelas atividades tradicionais e populares desenvolvidas na beira-rio, para reduzi-la a lugar de contemplação, lazer e turismo, já sob o novo nome de orla. Porém, tais projetos de requalificação, assim como outros implementados na beira do rio, como o Feliz Lusitânia e o Mangal das Garças, desconsideram as demais possibilidades de uso desse elemento, por exemplo, não facilitando a circulação fluvial. Em tais espaços, elementos como o Píer das Onze Janelas e o Memorial das Embarcações, fazem 
referência a essa circulação sobre as águas, a qual é negada no projeto, fazendo-se, assim, o jogo de presença e ausência comum à maioria das intervenções urbanísticas de Belém. Esse jogo tem por base a análise de Lefebvre (2006), no qual ele pensa o espaço concebido no sentido de representações simulantes-dissimuladas, o que, para Trindade Jr (2013), é nítido nos espaços requalificados citados, uma vez que os projetos de intervenção contêm elementos que se referem às relações sociais com o rio, mas impossibilitam suas práticas, e utilizam da toponímia para ratificar "uma prática que induz ao esquecimento dos antigos nomes 'trapiche', 'cais', 'doca', responsáveis por identificar esses atracadouros, tão presentes na vida cotidiana dos que acessam o rio" (TRINDADE JR, 2013, p. 507).

Considerando que, no decorrer de um processo, há uma relação entre os interesses dos agentes e a representação do espaço, as mudanças nos interesses acarretam transformações na concepção de tais processos e, portanto, na própria concepção do espaço, o que se exemplifica, no caso da análise de autores sobre a patrimonialização, com o relato de Canclini (1999). Ele afirma que no México e em outros países, a legislação, as declarações e os debates sobre o patrimônio mostram um movimento triplo de redefinição: no primeiro, deve-se incluir não apenas as expressões mortas, ou do passado, mas também os bens atuais visíveis e invisíveis; no segundo, as políticas patrimoniais de conservação e gestão do que foi produzido no passado se estendem aos usos que relacionam esses bens com as necessidades contemporâneas, e, no terceiro, contra a seleção privilegiada de bens produzidos pelas classes hegemônicas, há o reconhecimento do que é produzido pelas classes populares.

No Brasil, Bispo (2011), em sua análise sobre as políticas culturais, observa que:

(...) a atuação do poder público com relação aos bens histórico-culturais passou nas décadas de 30 e 40, e nos governos militares, de "conservacionista-monumentalista" e muito presente, para liberal e "mercantil", a partir de meados dos anos 80, e assim permaneceu até início dos anos 2000. A partir de 2003, no primeiro mandato do presidente Lula, houve um retorno à institucionalização da área, mas desta vez não com uma visão "conservacionista-monumentalista", mas sim "participacionista" (BISPO, 2011, p. 105).

No que se refere ao processo de turistificação, Malta (2018), em sua análise sobre as políticas públicas brasileiras antes e depois da criação do Ministério do Turismo, observa a predominância economicista nessas políticas, as quais seguem uma tendência global de concepção de desenvolvimento. Com base em Souza (2015), ele afirma que:

Fica claro, portanto, nas instituições elaboradoras das políticas públicas de turismo, o predomínio da perspectiva tradicional de desenvolvimento, fortemente caracterizada pelo que Souza (2015, p. 262) aponta como "vícios" inerentes às teorias de desenvolvimento ancoradas nos marcos da ideologia capitalista do desenvolvimento econômico: "etnocentrismo (mais especificamente eurocentrismo), teleologismo (isto é: etapismo, evolucionismo, historicismo) e economicismo" (MALTA, 2018, p. 80). 
Desse modo, as concepções das políticas de turismo e de patrimônio, analisadas pela dimensão da representação do espaço, interferem nas práticas espaciais e nos espaços de representação, podendo gerar, no atual momento do modo de produção capitalista, impactos negativos sobre os bens culturais que não se adaptam à lógica do mercado.

\section{Considerações Finais}

A análise dos processos de turistificação e patrimonialização pode ser feita sob a perspectiva da produção do espaço, na qual, conforme Lefebvre (2013), o espaço é socialmente produzido e se apresenta pela tríade percebido-concebido-vivido, ou, em outras palavras, na prática espacial, na representação do espaço e no espaço de representação.

Assim, considerando que, para o referido autor, a dimensão da representação do espaço está relacionada ao modo como planejadores e tecnocratas o concebem, o presente estudo buscou analisar a turistificação e a patrimonialização por essa dimensão, dado que a definição dos bens que devem ser preservados e/ou preparados para compor a oferta turística é feita por técnicos e planejadores.

A partir das contribuições dos autores elencados para esse estudo, a exemplo de Trindade Jr (2013), observou-se que os referidos processos têm se desenvolvido, em geral, de modo a buscar favorecer alguns grupos, desconsiderando-se as dimensões das práticas espaciais e dos espaços de representação o que, por consequência, se traduz em insucessos de diversos projetos.

\section{Referências Bibliográficas}

BISPO, M. N. Políticas públicas e o patrimônio histórico: das primeiras ações a economia da cultura. Revista Contemporânea (UERJ Online), v. 9, n. 1, p. 94-107, 2011. Disponível em: https://www.e-publicacoes.uerj.br/index.php/contemporanea/article/view/1253/1587. Acesso em: 03 jan. 2019.

BOURDIEU, P. Questões de sociologia. Lisboa: Edições Fim de Século, 2003.

BRASIL. Segmentação do turismo e o mercado. 1 ed. Brasília: Ministério do Turismo, 2010a.

BRASIL. Turismo Cultural: orientações básicas. 3. ed. Brasília: Ministério do Turismo, 2010b.

CANCLINI, N. G. Los usos sociales del patrimonio cultural. In: AGUILAR CRIADO, E. (Org.). Patrimonio Etnológico: nuevas perspectivas de estudio. Andalucía: Consejería de Cultura, 1999.

CARLOS, A. F. A. Da "organização" à "produção" do espaço no movimento do pensamento geográfico. In: CARLOS, A. F. A.; SOUZA, M. L.; SPOSITO, M. E. B. A produção do espaço urbano: agentes e processos, escalas e desafios. São Paulo: Contexto, 2017a. 
. Turismo e Patrimônio: um aporte geográfico. In: PAES, M. T. D., SOTRATTI, M. A. Geografia, turismo e patrimônio cultural: identidades, usos e ideologias. São Paulo: Annablume, 2017b.

CHOAY, F. Alegoria do patrimônio. São Paulo: Unesp, 2001

COSTA, E. B. da. Cidades da patrimonialização global: simultaneidade totalidade urbana - totalidade-mundo. São Paulo: Humanitas, Fapesp, 2015.

CRUZ, R. C. A. Geografias do Turismo: de lugares a pseudo-lugares. São Paulo: Roca, 2007.

"Patrimonialização do patrimônio": ensaio sobre a relação entre turismo, "patrimônio cultural" e produção do espaço. GEOUSP: espaço e tempo, São Paulo, v. 1, n. 31, p. 95-104, 2012.

. Prefácio. In: PAES, M. T. D.; SOTRATTI, A. Geografia, turismo e patrimônio cultural: identidades, usos e ideologias. São Paulo: Annablume, 2017.

FIGUEIREDO, S. L. Espaços de cultura nas cidades: notas sobre o ordenamento, acessibilidade e turistificação. In: FIGUEIREDO, S. (Org.). Turismo, lazer e planejamento urbano e regional. Belém: NAEA, p. 79-92, 2008.

FRATUCCI, A. C. A dimensão espacial nas políticas públicas brasileiras de turismo: as possibilidades das redes regionais de turismo. 2008. Tese (Doutorado). Programa de Pós-Graduação em Geografia. Universidade Federal Fluminense. Niterói.

GOTTDIENER, M. A produção social do espaço urbano. 2. ed. São Paulo: Edusp, 2010.

HARVEY, D. A produção capitalista do espaço. São Paulo: Annablume, 2005.

LEFEBVRE, H. O pensamento marxista e a cidade. Póvoa de Varzim: Ulissea, 1972.

. Espaço e política. Belo Horizonte: Editora UFMG, 2008.

. La Producción del Espacio. Madrid: Capitan Swing, 2013.

MALTA, G. A. P. O turismo como projeto político e sua capacidade de indução ao desenvolvimento econômico: destinos indutores ou concentradores do desenvolvimento turístico regional em Minas Gerais? 2018. Tese (Doutorado). Programa de Pós-graduação em Geografia. Instituto de Geociência da Universidade Federal de Minas Gerais. Belo Horizonte - UFMG.

NIGRO, C. As dimensões culturais e simbólicas nos estudos geográficos: bases e especificidades da relação entre patrimônio cultural e geografia. In: PAES, M. T. D.; OLIVEIRA, M. R. S. (Org.). Geografia, turismo e patrimônio cultural. São Paulo: Annablume, p. 55-80, 2010. 
PAES, M. T. D. Patrimônio cultural, turismo e identidades territoriais um olhar geográfico. In: BARTHOLO, R.; BURSZTYN, I.; SANSOLO, D. (Org.). Turismo de base comunitária: diversidade de olhares e experiências brasileiras. Rio de Janeiro: Letra e Imagem, 2009.

RIBEIRO, R. W. Patrimônio, discurso e prática: incursões sobre democracia e cidadania a partir do Rio de Janeiro e o patrimônio mundial. In: PAES, M. T. D.; SOTRATTI, M. A. (Org.). Geografia, turismo e patrimonio cultural. Identidades, usos e ideologias. São Paulo, Anablume, p. 45-66, 2017.

SÁNCHEZ, F. A Reinvenção das cidades na virada de século: agentes, estratégias e escalas de ação política. Revista de Sociologia e Política. n. 16, p. 31-49, 2001. Disponível em: http://www.scielo.br/ pdf/rsocp/n16/a03n16.pdf. Acesso em: 02 fev. 2019.

SCHMID, C. A teoria da produção do espaço de Henri Lefebvre: em direção a uma dialética tridimensional. GEOUSP: Espaço e Tempo (Online), n. 32, p. 89-109, 2012. Disponível em: https://doi.org/10.11606/issn.2179-0892.geousp.2012.74284. Acesso em: 02 jan. 2019.

TRINDADE JR, S. C. C. da. Patrimônios, vivências e representações do espaço em políticas de requalificação urbana na amazônia. Espaço e Geografia (UNB), v. 16, p. 483-513, 2013. Disponível em: http://www.lsie.unb.br/espacoegeografia/index.php/espacoegeografia/article/view/266. Acesso em: 14 fev. 2019.

\footnotetext{
${ }^{1}$ O presente trabalho trata-se de pesquisa em andamento no Programa de Pós-Graduação em Geografia da Universidade Federal do Pará e está sendo realizado com o apoio da Coordenação de Aperfeiçoamento de Pessoal de Nível Superior (CAPES) - Código de Financiamento 001.

${ }^{2}$ Conforme Sanchez (2001, p. 47), trata-se da “(...) valorização de áreas da cidade e de segmentos sociais em detrimento de outros $(. . .)^{\prime \prime}$.
} 